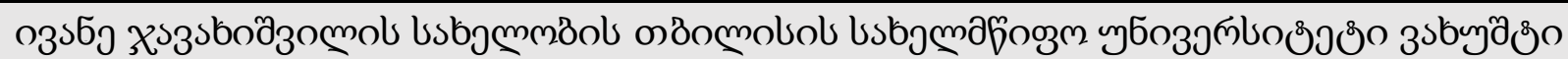

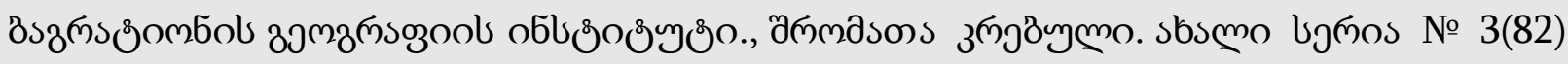

IVANE JAVAKHISHVILI TBILISI STATE UNIVERSITY VAKHUSHTI BAGRATIONI

INSTITUTE OF GEOGRAPHY COLLECTED PAPERS NEW SERIES № 3(82)

„ENVIRONMENT AND GLOBAL WARMING“ PROCEEDINGS OF INTERNATIONAL

CONFERENCE Dedicated To The 100th Birthday Anniversary Of Academician Feofan Davitaya

TBILISI 2011

\title{
On Problem of Calculation of Condensation Moisture in The Caves
}

\section{Kukuri Tsikarishvili ${ }^{1}$, Omar Lanchava ${ }^{2}$}

${ }^{1}$ Vakhushti Bagrationi Institute of Geography, Tbilisi, Georgia;

${ }^{2} \mathrm{G}$. Tsulukuidze Mining Institute, Tbilisi, Georgia;

E-mail: kukuritsikarishvili@ymail.com

Microclimate of karst caves are formed by the simultaneous process of heat and moisture (mass) exchange in the double-component thermodynamic system of "cave air - environment rock massif". Cave formations in this case are belonged to the rock massif. The simultaneous heat-masstransferring process can be considered as a simple process of transferring heat and mass, or isolation of heat transfer itself and the occurrences of evaporation and condensation for the purpose of simplifying the evaluation of the rests. Accordingly, relatively reliable must be the observations results on occurrences of evaporation and condensation in case when it is possible to isolate indicated simple processes from each other.

Though the importance of condensation precipitation is great in the annual balance of underground karst waters and it has a substantial impact on intensity of karsting processes and is of particular importance in formation of underground or ground waters of karst areas, this issue is considered oppositely in speleological references. Most of the researchers (S. Dolgov, M. Preobrazhenskaia, P. Koloskov) consider, that precipitation play the substantial role in the balance of underground karst sources and their feeding based on the data of V. Dublianskii (DUBLIANSKII V. N., 1977), but to his mind, even the opposite idea has its followers (M. Abramova, A. Lebedev, A. Schvebs).

It is notable that even for one and the same cave the different results are achieved by different authors that can be explained by the different approaches to the problem and complexity of measuring on locations. It should be taken into account the circumstances that the isolated moisture amount depends on volume of the cavity, as well as on intensity of air exchange and surface air vapor resilience in the system of "cave air - environment rock massif", et al. In addition, reliable measurement of the speed and discharge of the air stream is complicated due to the objective and subjective reasons.

Researches and observations on locations carried out by us in the karst caves of West Georgia first of all aimed at identification of the amount of condensation precipitation isolated in the karst 
cavities according to the seasons, and on the other hand, to test the equity of present calculation formulas for the caves in the Caucasus generally.

As a result of observations on locations, it has been stated by us that the occurrences of evaporation and condensation in the caves of medium and foothills limestone massifs are underway in the isothermal conditions basically, as the air temperature in the observation points along to all caves are unchangeable during the whole year practically.

We used the formula of V. Obolenskii (OBOLENSKII V.P., 1944).), worked up by V. Dublianskii (DUBLIANSKII V. N., 1977), OBOLENSKII V.P. (1944), in order to analyze the observations on locations:

$$
\mathrm{Q}=\operatorname{IVT}\left(\mathrm{e}_{1}-\mathrm{e}_{2}\right)
$$

where: Q - amount of condensation moisture, gr;

I - air exchange coefficient in the cave (1,5 - in average);

$\mathrm{V}$ - cavity volume, $\mathrm{m}^{3}, \mathrm{~V}=1,5.10^{6} \mathrm{~m}^{3}$;

$\mathrm{T}$ - duration of condensation process, daily (166).

$\mathrm{e}_{1}$ - surface air water vapor resilience, $\mathrm{mm} ; \mathrm{e}_{1}=14,7 \mathrm{~mm}$;

$\mathrm{e}_{2}-$ cave air vapor resilience, $\mathrm{mm}$. $\mathrm{e}_{2}=10,9 \mathrm{~mm}$.

$$
\mathrm{Q}=\mathrm{qv} .86400 \text {, }
$$

where: Q - amount of condensation moisture, gr;

$\mathrm{q}$ - water vapor resilience, $\mathrm{mm}$;

$\mathrm{V}$ - cavity volume, $\mathrm{m}^{3}$.

The first method is based on the identification of difference among values of surface atmospheric precipitation and the runoff at defined area of the cave. In addition, it must be foreseen the values of possible evaporation and the runoff percolated in the underground cracks. During the condensation process we have to do with the caves or the volume objects, which may contain the other cavities, foreseeing of which is related to the great complications, and sometimes it is even impossible.

The second method is based on the following facts: on the walls and ceiling of the cave the water vapor condensation occurs from the air with high temperature saturated with moisture; as it is known, the speed of air stream intruded in the underground, as well as the area of entry's cross section and the humidity content of the air, the amount of isolated moisture due to condensation of given area for given observation time period can be calculated. It is supposed that the evaporationcondensation is a dynamic process and maybe we will have to do with oversaturated water vapor, as a lack of the dust particles - the condensation cores is a general occurrence and it is also supposed that the mountain massif environment and the cave formations are mainly of hygroscope and hygrophilous by their nature. 
According to the formula (1), analysis of the results of observations of the entire period (MayOctober, 1970-1980) for the Akhali Athoni Cave resulted in amount of condensation moisture as $\mathrm{Q}=1414,0 \mathrm{~m}^{3}$, and by the formula (2) - as $\mathrm{Q}=1414,6 \mathrm{~m}^{3}$, or obtained results differ from each other only with $0.25 \%$ and both of formulas are of the same exactness for given conditions.

By our supposed calculations total amount of condensation moisture in the Tskaltubo cave is $1870-2000 \mathrm{~m}^{3}$ or $115-120 \mathrm{~mm} /$ year, which is $6,3 \%$ of annual sum of surface atmospheric precipitation $(1818 \mathrm{~mm})$ and $25 \%$ of the seasonal one $(460 \mathrm{~mm})$. Proceeding from this the $259,2 \mathrm{~m}^{3}$ of condensation precipitation is observed in September and it is lower $\left(216 \mathrm{~m}^{3}\right)$ in June.

As it was expected, process of condensation is intense during the warm spell of the year, when on the surface the water vapor resilience exceeds the resilience under the ground. In the caves of hills and foothills, karst regions of Western Georgia the condensation processes are characterized with sharp annual course. The process starts in April (0.06\%), intensifies in May (4.3\%) and June (17\%), and reaches its maximum in July (32,2\%) and August (34\%), (Table).

Table. Mean monthly and daily values of water vapor condensation (+) and evaporation (-) in the Akhali Athoni Cave (April-October, 1970-1980)

\begin{tabular}{|c|c|c|c|c|}
\hline \multirow[t]{3}{*}{ Month } & \multicolumn{4}{|c|}{ Condensation, $\mathrm{m}^{3}$} \\
\hline & \multicolumn{2}{|c|}{ Monthly mean } & \multicolumn{2}{|c|}{ Daily } \\
\hline & Evaporation & Condensation & Evaporation & Condensation \\
\hline January & -482.3 & & -15.55 & \\
\hline February & -409.9 & 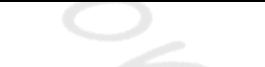 & -14.63 & \\
\hline March & -345.0 & & -11.12 & \\
\hline April & -146.2 & 0.97 & -5.84 & 0.13 \\
\hline May & & 60.45 & $\sqrt{2}$ & 1.95 \\
\hline June & & 230.8 & & 7.99 \\
\hline July & & 456.39 & & 14.72 \\
\hline August & & 483.0 & & 15.58 \\
\hline September & & 161.75 & & 5.39 \\
\hline October & -90.72 & 17.64 & -3.94 & 0.14 \\
\hline November & -234.0 & & -7.8 & \\
\hline December & -383.62 & & -12.37 & \\
\hline Annual & -2091.64 & & -71.25 & \\
\hline
\end{tabular}

During the cold spells of the year in most of the caves the evaporation takes place by poorly expressed daily variation. Difference among the water vapor resiliencies reaches its maximum in January and February (4-5 mm). In March the daily course of evaporation is well expressed - it is 
reduced at night and increased at daytime. At that moment the occurrence of condensation is possible in some of the caves of foothills karst.

Maximum value $\left(482.3 \mathrm{~m}^{3}\right)$ of evaporation is observed in January. In April $\left(146.2 \mathrm{~m}^{3}\right)$ and October $\left(90.7 \mathrm{~m}^{3}\right)$ it is reduced considerably (Fig.). Though this value does not have any impact on the water balance of siphon lakes located in the Akhali Athoni Cave, as in the huge halls of the cave due to complex ventilation conditions the evaporated water is isolated again as dews on the cold walls of the cave.

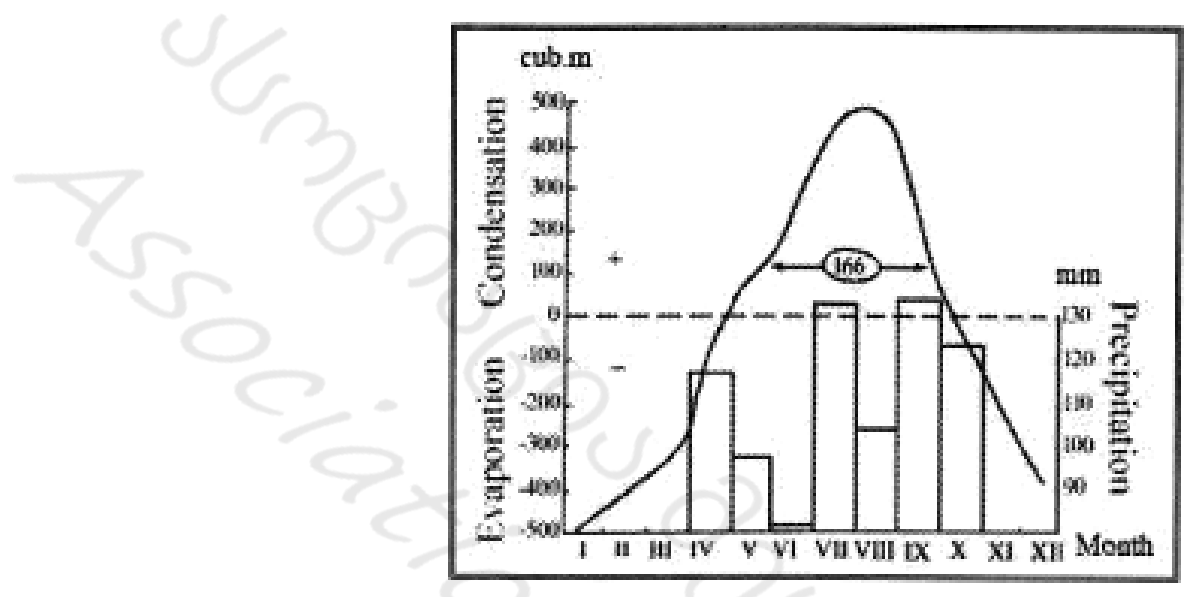

Fig. Annual course of condensation (+) and evaporation (-) in the foothills' karst caves (166 duration of condensation process)

It should be taken into account the horizontal or surface precipitation (dew, ice crust, hoarfrost, et al.). In the low-mountain landscape zone the number of days with dew equals to 110-130. According to M. Kordzakhia (KORDZAKHIA M., 1970) in the low-mountain landscape zone of Western Georgia, where the area is characterized with moderate humid climate and rich deciduous vegetation, the horizontal precipitation should not be less than 1300-1500 mm. Taking into account the mentioned factors, the condensation moisture in the low-mountain karst caves makes only 2.6$3.6 \%$ of the atmospheric and surface precipitations. In these conditions the inflow of infiltrated waters is more intensive in the caves than the precipitations isolated by the condensation of water vapor.

It is notable that in the Akhali Athoni Cave the total amount of condensation precipitation is more than in the karst caves in the North that can be explained by the closeness of Akhali Athoni Cave to the sea coast and its location in the humid subtropical zone. Here, under the ground, the condensation process is much longer than that of the caves located in the northern latitudes.

Condensation precipitations are of hydrocarbonate or of natrium-calcium by its chemical composition, mineralization of which reaches $0.3-0.5 \mathrm{gr} / \mathrm{l}$. In the moment of origin the condensation precipitations are characterized by zero mineralization and high aggressiveness. As a rule, in the caves it should be of main importance in modeling of underground karst microforms (Trombe F., 1952, Ustinova T.I., 1963, Gvozdetskii N.A., 1972, Gergedava B.A., 1983). Though, on the basis of observations conducted in the adjacent karst regions (Alek, Atskhu, Vorontsov) of Western Caucasus, it was stated, that the condensation corrosion $\left(50.7 \mathrm{~m}^{3}\right.$ per year, or $\left.2.9 \%\right)$ is unimportant 
in formation of karst cavities, though the corrosion induced by condensant plays certain role in modeling of cave rocks.

Thus, amount of condensation moisture of Akhali Athoni Cave makes $1400 \mathrm{~m}^{3}$ per year. For assessment of its amount application of the formulas (1) and (2) are available. As researches showed, isolation of condensation precipitation is characterized with sharp zonality according to the altitude of the area, and by chemical composition the moisture obtained due to water vapor condensation is of hydrocarbonate or of natrium-calcium, mineralization of which does not exceed 0.3-0.5 gr/1.

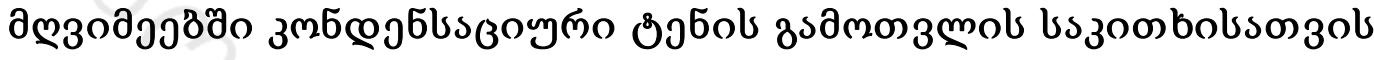 зУзупо боль๓о

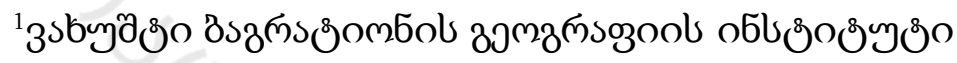

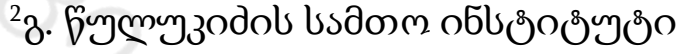 \\ jm.ơmbðs: kukuritsikarishvili@ymail.com}

\section{๓๐षัฒyว}

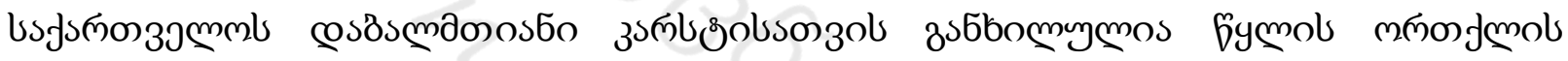

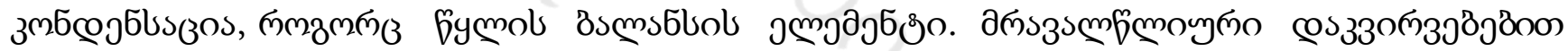

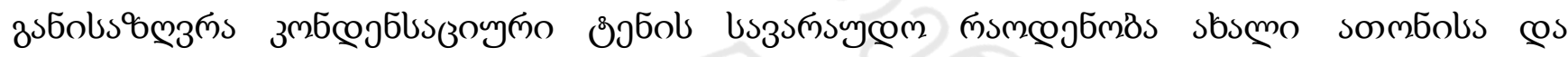

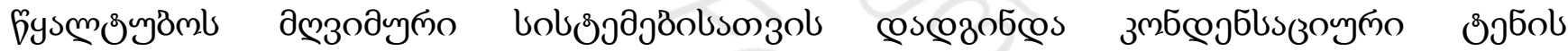

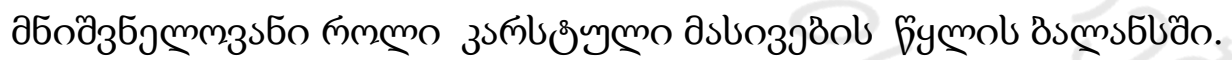

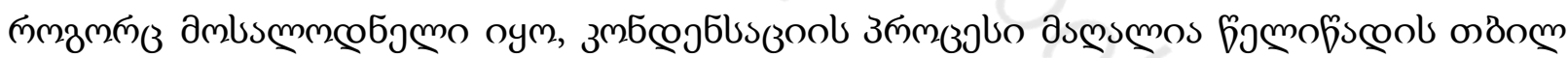

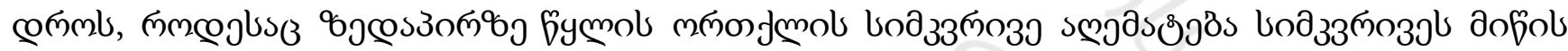

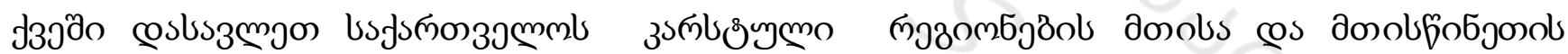

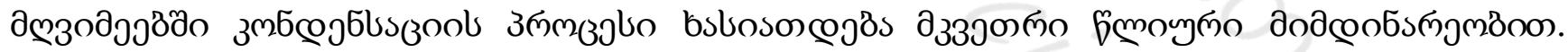

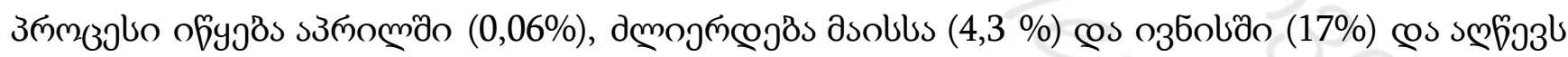

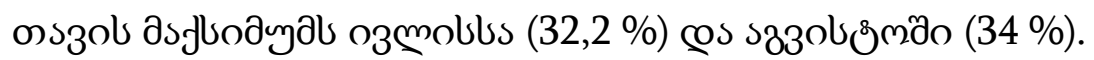

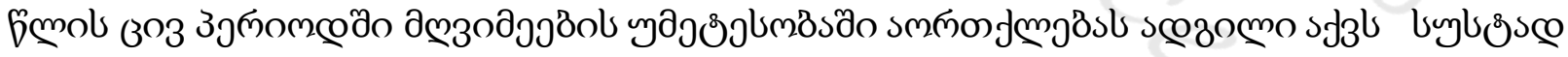

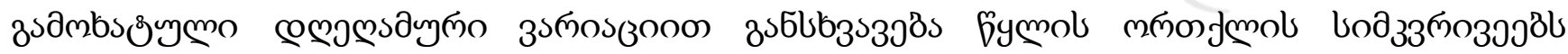

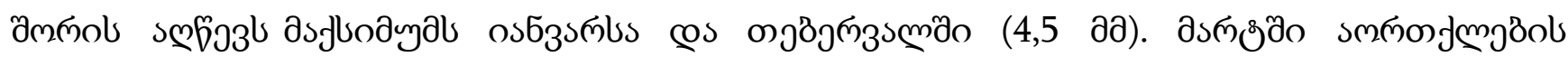

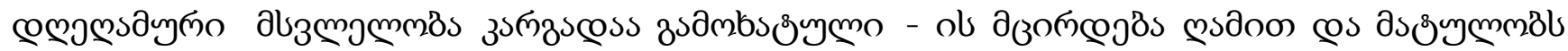

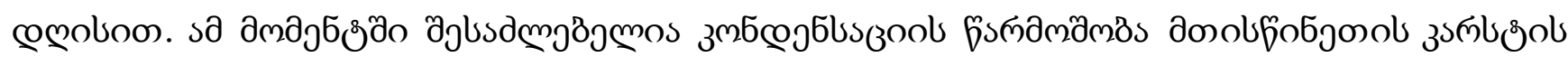
६мзоло дщзодјдо.

\section{REFERENCES}

Dublianskii V. N. (1977). Karst Caves And Mines Of The Mountainous Crimea. I.. (In Russian);

Dublianskii V. N., Kiknadze Tl, Kolomiets AA (1983). Bulletin Of An. Gssr, V.110, N 2;

Gergedava BA. (1983). Underground Landscapes. Tbilisi (In Russian). 
Gvozdetskii NA. (1972). Problems Of Studying Karst And Practice. Moscow (In Russian);

Kordzakhia M. (1970). Dew In The Kolkheti Lowland. Proceedings Of Georgian Ssr Geographical Society, V. 11, Tbilisi (In Georgian);

Obolenskii VP. (1944). Course Of Meteorology. Moscow-Sverdlovsk, (In Russian);

Trombe F. (1952). Traite De Speleologie. Paris;

Ustinova TI (1963). Method Of Calculation Condensation Moisture In The Caves. In The Book: Methodology Of Studying Karst. Perm, Issue 9, (In Russian). 